\title{
Research on an Improved Method for Permanent Magnet Synchronous Motor
}

\author{
Yingpei Liu, ${ }^{1}$ Tao Gao, ${ }^{2}$ and Guo $\mathrm{Li}^{3}$ \\ ${ }^{1}$ School of Electrical and Electronic Engineering, North China Electric Power University, Baoding, Hebei 071003, China \\ ${ }^{2}$ Department of Automation, North China Electric Power University, Baoding, Hebei 071003, China \\ ${ }^{3}$ School of Management and Economics, Beijing Institute of Technology, Beijing 100081, China
}

Correspondence should be addressed to Yingpei Liu; liuyingpei_123@126.com

Received 20 June 2014; Revised 19 July 2014; Accepted 14 August 2014; Published 1 September 2014

Academic Editor: Tinggui Chen

Copyright (C) 2014 Yingpei Liu et al. This is an open access article distributed under the Creative Commons Attribution License, which permits unrestricted use, distribution, and reproduction in any medium, provided the original work is properly cited.

\begin{abstract}
In permanent magnet synchronous motor (PMSM) traditional vector control system, PI regulator is used in the speed loop, but it has some defects. An improved method of PMSM vector control is proposed in the paper. The active-disturbance rejection control (ADRC) speed regulator is designed with the input signals of given speed and real speed and the output of given stator current $q$ coordinate component. Then, in order to optimize ADRC controller, the least squares support vector machines (LSSVM) optimal regression model is derived and successfully embedded in the ADRC controller. ADRC observation precision and dynamic response of the system are improved. The load disturbance effect on the system is reduced to a large extent. The system anti-interference ability is further improved. Finally, the current sensor CSNE151-100 is selected to sample PMSM stator currents. The voltage sensor JLBV1 is used to sample the stator voltage. The rotor speed of PMSM is measured by mechanical speed sensor, the type of which is BENTLY 330500. Experimental platform is constructed to verify the effectiveness of the proposed method.
\end{abstract}

\section{Introduction}

With the advantages of high power density and high efficiency, permanent magnet synchronous motor (PMSM) is widely used in a variety of high performance electric drive fields. PMSM control method has been widely concerned and researched [1-17].

PMSM is nonlinear and is strongly coupling. In order to achieve high performance operation, the uncertainties and nonlinear impact on the system must be overcome. In traditional vector control system, PI regulator is adopted in the speed loop. PI controller structure is simple; nevertheless, its parameter robustness is poor and there are contradictions between speed and overshoot. PI control is difficult to meet the requirements of high performance operation.

Based on the preliminary research results, an improved method of PMSM control is proposed in the paper. The active-disturbance rejection controller (ADRC) is designed for speed loop. Then, in order to optimize ADRC controller, the least squares support vector machines (LSSVM) optimal regression model is derived and successfully embedded in the ADRC controller. ADRC observation precision and dynamic response of the system are improved. The load disturbances effect on the system is reduced to a large extent. The system anti-interference ability is further improved. Finally, different sensors sampling current, voltage, and rotor speed are used to finish experimental validation.

\section{PMSM Mathematical Model}

$d-q$ coordinate is chosen. The voltage equation of PMSM is as follows:

$$
\begin{gathered}
u_{d}=R_{s} i_{d}+p i_{d} L_{d}-\omega_{r} L_{q} i_{q}, \\
u_{q}=R_{s} i_{q}+p i_{q} L_{q}+\omega_{r} L_{d} i_{d}+\omega_{r} \psi_{r},
\end{gathered}
$$

where $u_{d}, u_{q}$ are stator voltage $d, q$ coordinate components; $i_{d}, i_{q}$ are stator current $d, q$ coordinate components; $R_{s}$ is stator resistance, $L_{d}, L_{q}$ are stator inductance; $\omega_{r}$ is rotor speed; $\psi_{r}$ is permanent magnet flux linkage; and $p$ is differential operator. 
The electromagnetic torque equation of PMSM is shown as follows:

$$
T_{e}=N_{p}\left(\psi_{r} i_{q}+\left(L_{d}-L_{q}\right) i_{d} i_{q}\right) .
$$

For surface PMSM, $L_{d}=L_{q}$. Equation (3) can be derived from (2):

$$
T_{e}=N_{p} \psi_{r} i_{q}
$$

The motion equation of PMSM is as follows:

$$
J \frac{d}{d t}\left(\frac{\omega_{r}}{N_{p}}\right)+B\left(\frac{\omega_{r}}{N_{p}}\right)=T_{e}-T_{L},
$$

where $J$ is rotational inertia; $B$ is friction coefficient; and $T_{L}$ is the load.

\section{Design of ADRC Speed Regulator}

3.1. ADRC Theory. ADRC controller is composed of tracking-differentiator (TD) and extended state observer (ESO) and nonlinear state error feedback control rate (NLSEF) [18, 19].

First-order system is assumed as follows:

$$
\begin{gathered}
\dot{x}=f(x, t)+b u, \\
y=x .
\end{gathered}
$$

The TD model of the first-order system (5) is as follows:

$$
\dot{v}_{1}=- \text { fst }\left(v_{1}-v, r, T\right),
$$

where $\operatorname{fst}\left(v_{1}, r, T\right)$ is defined as

$$
\begin{gathered}
d=r T ; \quad d_{0}=d T ; \\
y_{\mathrm{TD}}=v_{1} ; \quad a_{0}=\left(d^{2}+8 r\left|y_{\mathrm{TD}}\right|\right)^{1 / 2} ; \\
a= \begin{cases}\frac{\left(a_{0}-d\right)}{y_{\mathrm{TD}}}, & \left|y_{\mathrm{TD}}\right|>d_{0}, \\
\mathrm{~T} & \left|y_{\mathrm{TD}}\right| \leq d_{0},\end{cases} \\
\text { fst }=- \begin{cases}\frac{r a}{d}, & |a| \leq d, \\
r \operatorname{sgn}(a), & |a|>d,\end{cases}
\end{gathered}
$$

where $v_{1}$ is the tracking signal of $v ; r$ is the tracking speed factor; and $T$ is the sample period.

The ESO model of first-order system (3) is as follows:

$$
\begin{gathered}
e=z_{1}-y, \\
\dot{z}_{1}=z_{2}-\beta_{01} * \operatorname{fal}\left(e, \alpha_{1}, \delta\right)+b u, \\
\dot{z}_{2}=-\beta_{02} * \operatorname{fal}\left(e, \alpha_{2}, \delta\right),
\end{gathered}
$$

where $z_{1}$ is the tracking signal of $y ; z_{2}$ is the estimation value of disturbance; $\alpha_{1}, \alpha_{2}$ are nonlinear factors; $\delta$ is filter

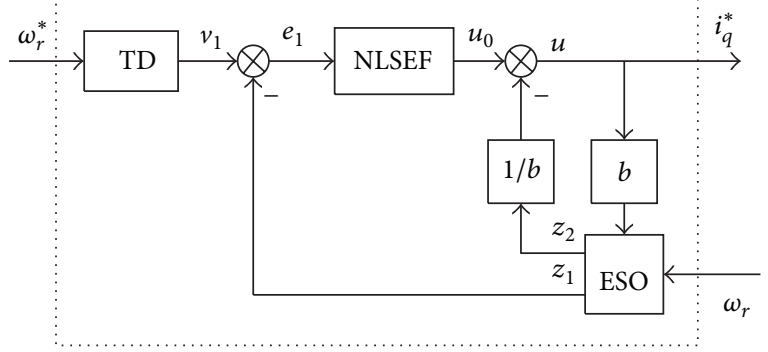

FIGURE 1: Diagram of the speed regulator based on ADRC.

factor; $\beta_{01}, \beta_{02}$ are the parameters; and fal $(e, \alpha, \delta)$ is nonlinear function:

$$
\operatorname{fal}(e, \alpha, \delta)= \begin{cases}|e|^{\alpha} \operatorname{sgn}(e), & |e|>\delta, \\ \frac{e}{\delta^{1-\alpha}}, & |e| \leq \delta .\end{cases}
$$

NLSEF model of system (3) is as follows:

$$
\begin{gathered}
e_{1}=v_{1}-z_{1}, \\
u_{0}=\beta_{1} \operatorname{fal}\left(e_{1}, \alpha_{3}, \delta_{1}\right), \\
u=u_{0}-\frac{z_{2}}{b},
\end{gathered}
$$

where $\delta_{1}$ is filter factor and $\alpha_{3}$ is nonlinear factor.

3.2. Speed Regulator Design. Equation (11) is obtained from (3) and (4):

$$
\frac{d \omega_{r}}{d t}=\frac{N_{p}^{2} \psi_{r} i_{q}}{J}-\frac{N_{p} T_{L}}{J}-\frac{B \omega_{r}}{J} .
$$

Based on ADRC theory, $T_{L}, B$, and $J$ are seen as disturbance velocity loop. The disturbance is denoted as $w(t)$, $w(t)=-\left(N_{p} T_{L} / J\right)-\left(B \omega_{r} / J\right)$. Equation (12) is got as follows:

$$
\frac{d \omega_{r}}{d t}=\frac{N_{p}^{2} \psi_{r} i_{q}}{J}+w(t) .
$$

The output of the speed loop is the given value of $i_{q}$, which is $i_{q}^{*}$. Then, (13) is got:

$$
\frac{d \omega_{r}}{d t}=\frac{N_{p}^{2} \psi_{r} i_{q}^{*}}{J}+w(t) .
$$

Speed regulator based on ADRC with $\omega_{r}^{*}$ and $\omega_{r}$ as the input signals and $i_{q}^{*}$ as the output signal is designed according to (6), (8), and (10). The diagram of speed regulator based on ADRC is shown in Figure 1.

\section{Design of LSSVM-ADRC Controller}

4.1. LSSVM Theory. Assume training sample data $\left\{\left(x_{k}, y_{k}\right) \mid\right.$ $k=1,2, \ldots, N\}$, while $x_{k} \in R^{n}$ is the input data and 


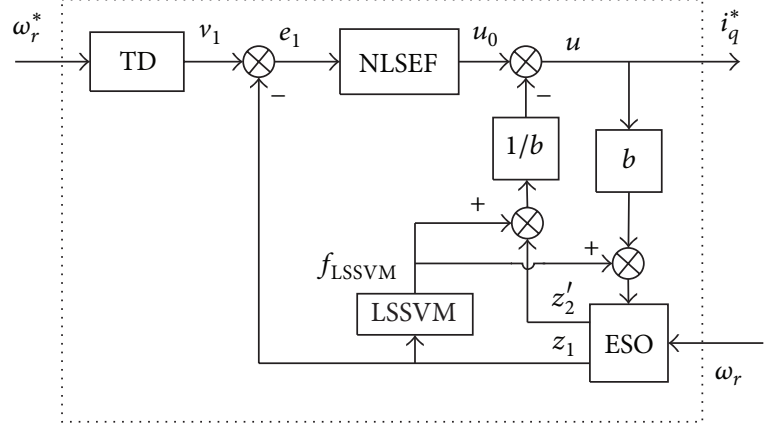

FIgURE 2: Diagram of LSSVM-ADRC controller.

$y_{k} \in R$ is the output data. The goal of LSSVM is to construct a regression model as follows [20-23]:

$$
y(x)=w^{T} \varphi(x)+b,
$$

where $w \in R^{n}$ is weight vector; $b \in R$ is the offset; and $\varphi(x)$ is the mapping function in kernel space.

LSSVM regression algorithm is to calculate the optimum as follows:

$$
\begin{aligned}
& \min \quad J(w, \varepsilon)=\frac{1}{2}\|w\|^{2}+\frac{1}{2} \xi \sum_{k=1}^{N} \varepsilon_{k}^{2} \\
& \text { s.t. } \quad y_{k}=w^{T} \varphi\left(x_{k}\right)+b+\varepsilon_{k} ; \quad k=1,2, \ldots, N,
\end{aligned}
$$

where $J$ is the optimized objective function; $\xi \in R$ is the regularization parameter; and $\varepsilon_{k} \in R$ is the relaxation factor of insensitive loss function. lows:

The corresponding Lagrange function is shown as fol-

$$
L=\frac{1}{2}\|w\|^{2}+\frac{1}{2} \xi \sum_{k=1}^{N} \varepsilon_{k}^{2}-\sum_{k=1}^{N} a_{k}\left(w^{T} \varphi\left(x_{k}\right)+b+\varepsilon_{k}-y_{k}\right),
$$

where $a_{k} \in R$ is Lagrange factor.

The partial derivation operation of $L$ is made, and then make it to zero. Equation (17) is got:

$$
\begin{gathered}
w=\sum_{k=1}^{N} a_{k} \varphi\left(x_{k}\right), \\
a_{k}=\xi \varepsilon_{k}, \\
\sum_{k=1}^{N} a_{k}=0, \\
w^{T} \varphi\left(x_{k}\right)+b+\varepsilon_{k}-y_{k}=0 .
\end{gathered}
$$

Thus, the optimization problem is transformed into solving the following linear equation:

$$
\left[\begin{array}{cc}
0 & \mathbf{1}^{T} \\
\mathbf{1} & \boldsymbol{\Omega}+\xi^{-1} \mathbf{I}
\end{array}\right]\left[\begin{array}{l}
b \\
\mathbf{a}
\end{array}\right]=\left[\begin{array}{l}
0 \\
\mathbf{y}
\end{array}\right]
$$

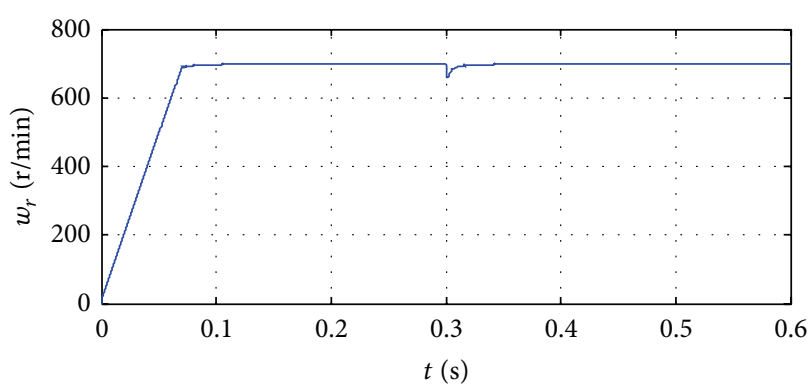

(a) Speed wave

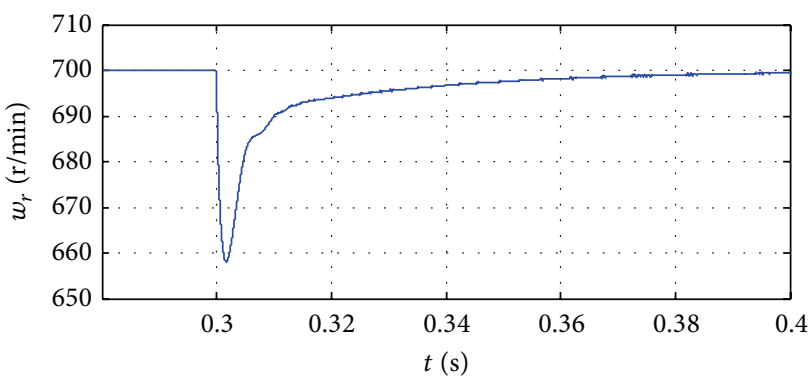

(b) Part of speed wave when load changes front and back

FIGURE 3: Simulation waves under ADRC method when given speed is $700 \mathrm{r} / \mathrm{min}$ and load changes from 0 to $3 \mathrm{~N} \cdot \mathrm{m}$ at $0.3 \mathrm{~s}$.

where $\mathbf{1}=[1,1, \ldots, 1]^{T} ; \mathbf{I}$ is an $N \times N$ unit matrix; $\mathbf{a}=$ $\left[a_{1}, a_{2}, \ldots, a_{N}\right]^{T} ; \mathbf{y}=\left[y_{1}, y_{2}, \ldots, y_{N}\right]^{T}$; and $\boldsymbol{\Omega}=\left\{\Omega_{i j}\right\}_{N \times N}$, $\Omega_{i j}=\varphi\left(x_{i}\right)^{T} \cdot \varphi\left(x_{j}\right)=K\left(x_{i}, x_{j}\right), i, j=1,2, \ldots, N$.

$K\left(x_{i}, x_{j}\right)$ is a kernel function. The approximation accuracy and computational efficiency are both considered in the paper; Gaussian RBF kernel function is chosen and shown as follows:

$$
K\left(x_{i}, x_{j}\right)=\exp \left(-\frac{\left\|x_{i}-x_{j}\right\|^{2}}{2 \zeta^{2}}\right)
$$

where $\zeta$ is a coefficient which decides the scaling extent of input variable in learning algorithm.

Define $\mathbf{M}=\mathbf{\Omega}+\boldsymbol{\xi}^{-1} \mathbf{I}$. The solution of (18) is expressed as follows:

$$
\begin{gathered}
\boldsymbol{\alpha}=M^{-1}(\mathbf{y}-b \mathbf{1}), \\
b=\frac{\mathbf{1}^{T} M^{-1} \mathbf{y}}{\mathbf{1}^{T} M^{-1} \mathbf{1}} .
\end{gathered}
$$
follows:

Therefore, the LSSVM approximation function is as

$$
y(x)=\sum_{k=1}^{N} a_{k} K\left(x, x_{k}\right)+b .
$$

4.2. LSSVM-ADRC Controller. In Figure 1, sample the output variables $z_{1}, z_{2}$ of ESO. Train LSSVM model to get the optimal regression model with $z_{1}$ as the input signal and $z_{2}$ as the output signal. Then, embed the LSSVM optimal regression 


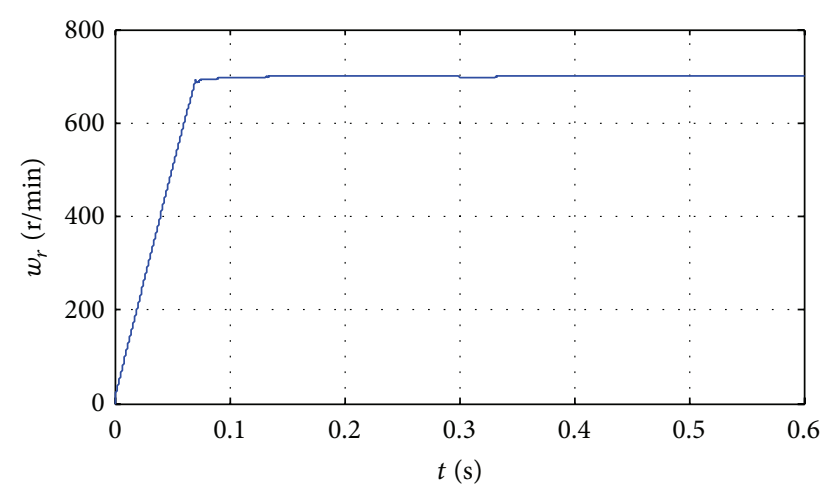

(a) Speed wave

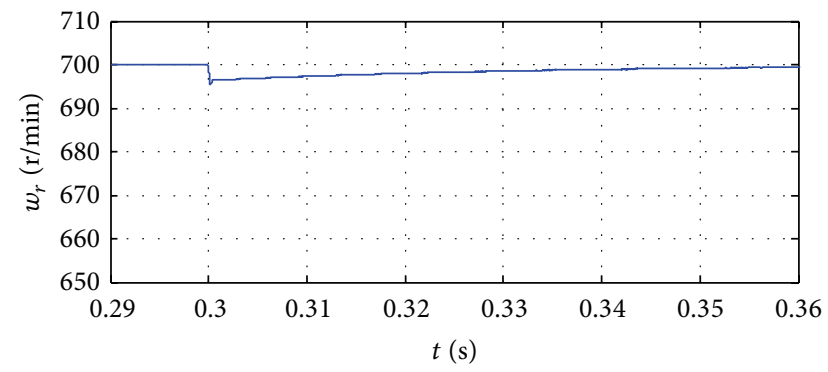

(b) Part of speed wave when load changes front and back

FIGURE 4: Simulation waves under LSSVM-ADRC method when given speed is $700 \mathrm{r} / \mathrm{min}$ and load changes from 0 to $3 \mathrm{~N} \cdot \mathrm{m}$ at $0.3 \mathrm{~s}$.

model into the ADRC controller. The diagram of LSSVMADRC is shown in Figure 2.

In Figure 2, the LSSVM model can estimate part of system disturbance $f_{\text {LSSVM }}$ according to the input signal $z_{1}$. $f_{\text {LSSVM }}$ and the other disturbance $z_{2}^{\prime}$ estimated by ESO compose the total disturbance. Therefore, it can be seen that the ADRC disturbances estimation burden has reduced and system response has been improved. Furthermore, the system antiinterference ability is enhanced. The mathematical model of LSSVM-ADRC controller is obtained:

$$
\begin{gathered}
\dot{v}_{1}=-\mathrm{fst}\left(v_{1}-\omega_{r}^{*}, r, T\right), \\
e=z_{1}-\omega_{r}, \\
\dot{z}_{1}=z_{2}^{\prime}-\beta_{01} \mathrm{fal}\left(e, \alpha_{1}, \delta_{1}\right)+b u+f_{\mathrm{LSSVM}}, \\
\dot{z}_{2}^{\prime}=-\beta_{02} \mathrm{fal}\left(e, \frac{\alpha_{1}}{2}, \delta_{1}\right), \\
e_{1}=v_{1}-z_{1}, \\
u_{0}=\beta_{1} \mathrm{fal}\left(e_{1}, \alpha_{2}, \delta_{2}\right), \\
u=u_{0}-\frac{\left(z_{2}^{\prime}+f_{\mathrm{LSSVM}}\right)}{b} .
\end{gathered}
$$

\section{Simulation and Experiment Results}

5.1. Simulation Result. Based on Matlab/Simulink, the system simulation model is constructed to carry out simulation.

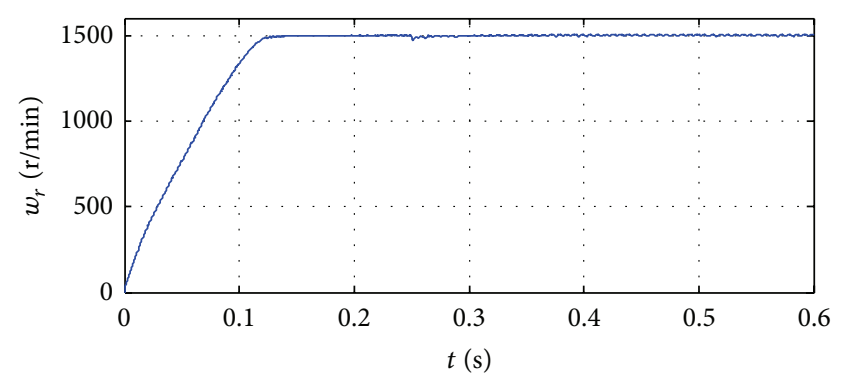

(a) Speed wave

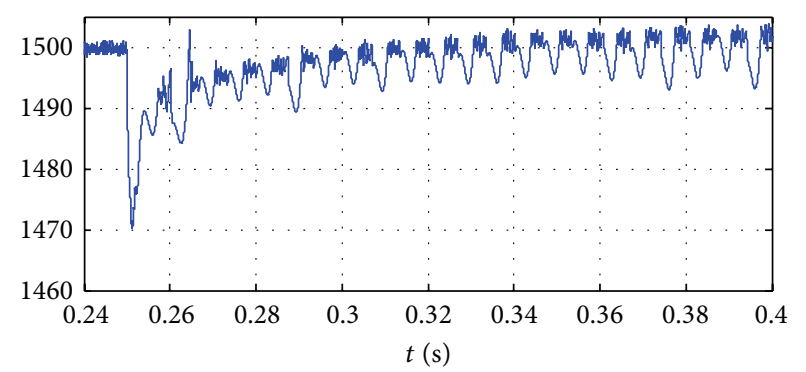

(b) Part of speed wave when load changes front and back

FIGURE 5: Simulation waves under ADRC method when given speed is $1500 \mathrm{r} / \mathrm{min}$ and load changes from $3 \mathrm{~N} \cdot \mathrm{m}$ to $6 \mathrm{~N} \cdot \mathrm{m}$ at $0.25 \mathrm{~s}$.

LSSVM training is programed using $\mathrm{m}$ file in Matlab. The main parameters of PMSM are as follows: $R_{s}=13 \Omega, \psi_{r}=$ $0.7 \mathrm{~Wb}$, and $N_{p}=2$.

(1) The given speed is $700 \mathrm{r} / \mathrm{min}$; at $0.3 \mathrm{~s}$ load torque changes from 0 to $3 \mathrm{~N} \cdot \mathrm{m}$. The speed waves are shown in Figures 3 and 4 under ADRC speed regulator and LSSVM-ADRC speed regulator, respectively.

From Figure 3, it can be seen that, based on ADRC speed controller, rotor speed instantly drops to $660 \mathrm{r} / \mathrm{min}$ when load suddenly changes, and then it reaches a steady state once again after 0.1 seconds. Contrastively, under LSSVMADRC speed controller in Figure 4, rotor speed drops to $695 \mathrm{r} / \mathrm{min}$ when load suddenly changes, and only after $0.06 \mathrm{~s}$ it reaches steady state again. The reason is LSSVM has reduced the burden on the ESO observation. The observation accuracy and system response speed have been improved under LSSVM-ADRC method.

(2) The given speed is $1500 \mathrm{r} / \mathrm{min}$; at $0.25 \mathrm{~s}$ load torque changes from $3 \mathrm{~N} \cdot \mathrm{m}$ to $6 \mathrm{~N} \cdot \mathrm{m}$. The speed waves are shown in Figures 5 and 6 under ADRC speed regulator and LSSVM-ADRC speed regulator, respectively.

From Figure 5, it can be seen that, based on ADRC speed controller, when load suddenly changes rotor speed drops from $1500 \mathrm{r} / \mathrm{min}$ to $1470 \mathrm{r} / \mathrm{min}$, and after that it reaches a steady state after 0.07 seconds. Contrastively, under LSSVMADRC speed controller in Figure 6, rotor speed drops from $1500 \mathrm{r} / \mathrm{min}$ to $1497 \mathrm{r} / \mathrm{min}$ when load suddenly changes, and only after $0.03 \mathrm{~s}$ it reaches a steady state again.

Combining the above simulation results under conditions of low speed and high speed, it can be concluded that, based 


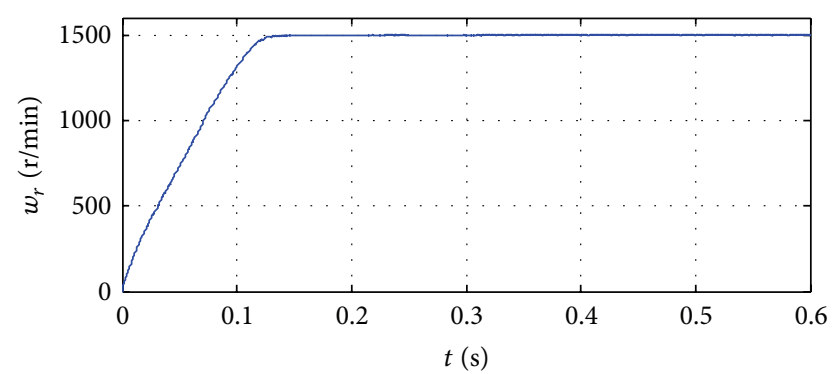

(a) Speed wave

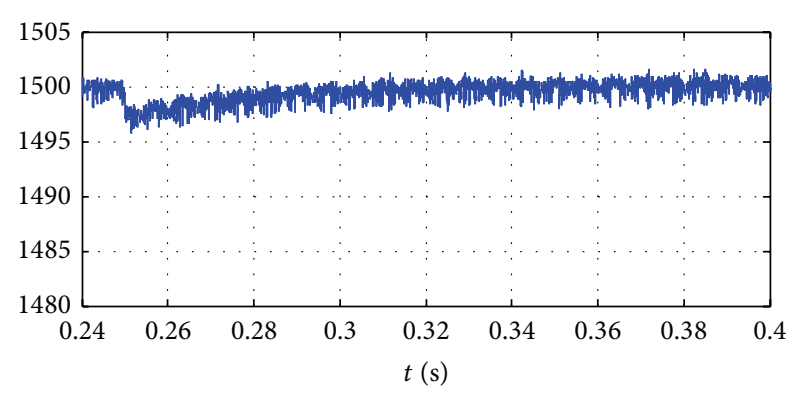

(b) Part of speed wave when load changes front and back

FIGURE 6: Simulation waves under LSSVM-ADRC method when given speed is $1500 \mathrm{r} / \mathrm{min}$ and load changes from $3 \mathrm{~N} \cdot \mathrm{m}$ to $6 \mathrm{~N} \cdot \mathrm{m}$ at $0.25 \mathrm{~s}$.

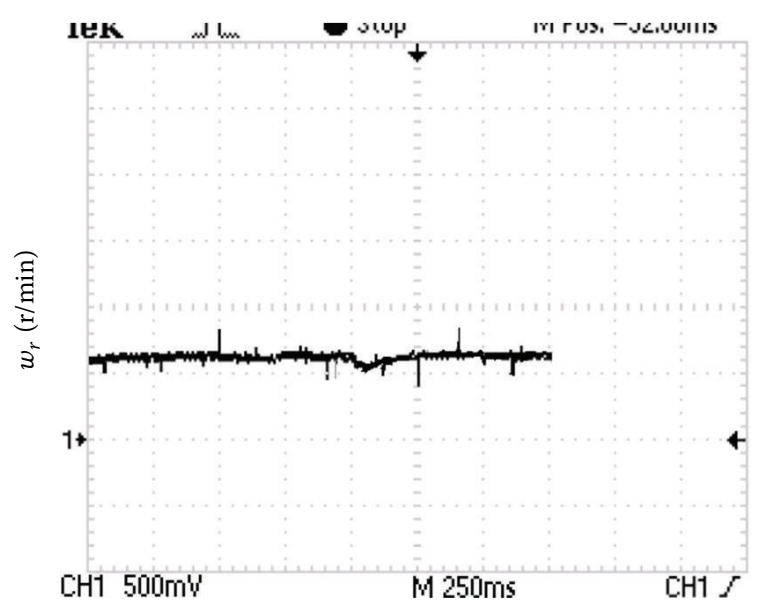

FIGURE 7: Experiment speed wave under ADRC method when given speed is $700 \mathrm{r} / \mathrm{min}$ and load changes from 0 to $3 \mathrm{~N} \cdot \mathrm{m}$.

on LSSVM-ADRC method, system responsiveness has been greatly improved; at the same time, system anti-interference ability has been improved to a large extent.

5.2. Experiment Result. To validate the performance of the proposed method, experimental study is conducted on a PMSM turbine. The motor parameters are the same as the simulation motor. The chip TI DSP TMS320F2812 is chosen as the control core. The AC-DC-AC main circuit structure is

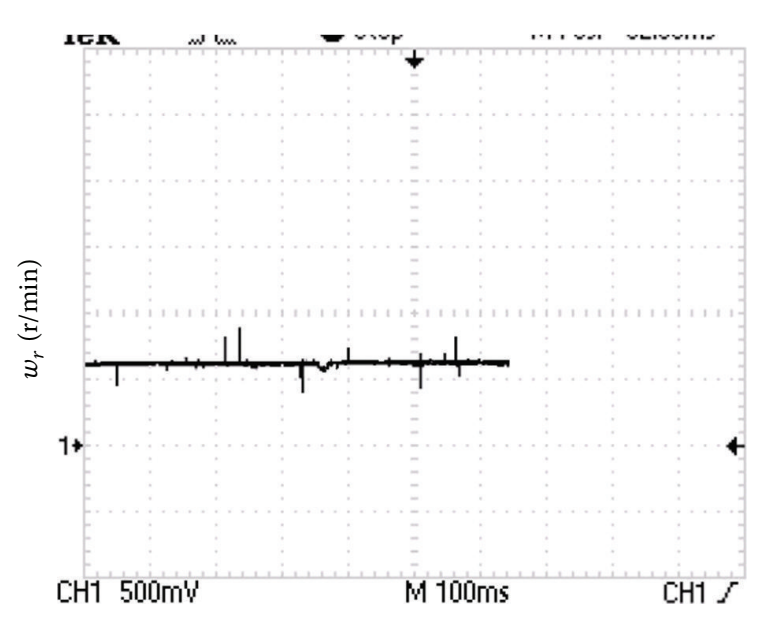

(a) Speed wave

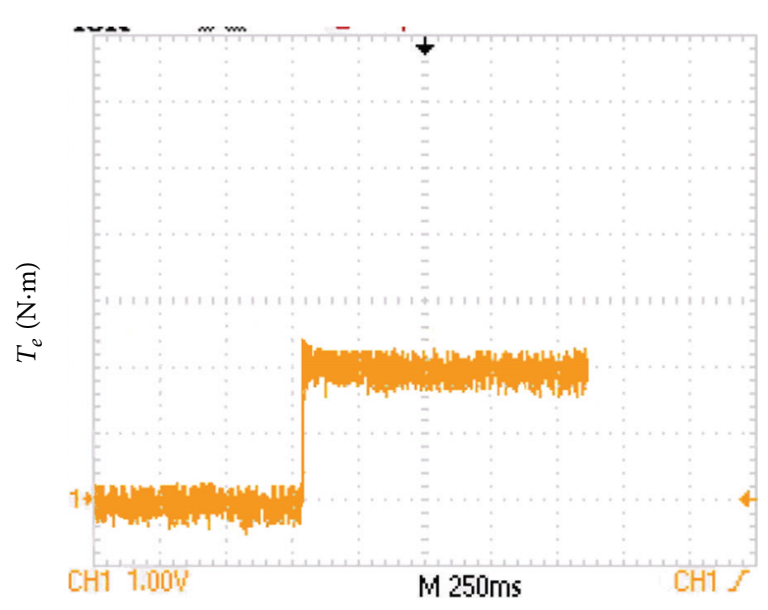

(b) Electromagnet torque wave

FIGURE 8: Experiment waves under LSSVM-ADRC method when given speed is $700 \mathrm{r} / \mathrm{min}$ and load changes from 0 to $3 \mathrm{~N} \cdot \mathrm{m}$.

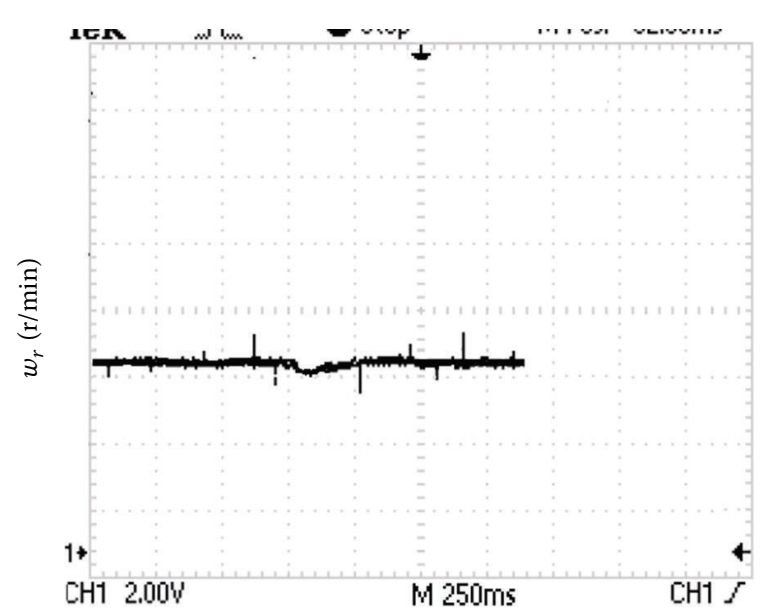

FIGURE 9: Experiment speed wave under ADRC method when given speed is $1500 \mathrm{r} / \mathrm{min}$ and load changes from $3 \mathrm{~N} \cdot \mathrm{m}$ to $6 \mathrm{~N} \cdot \mathrm{m}$. 


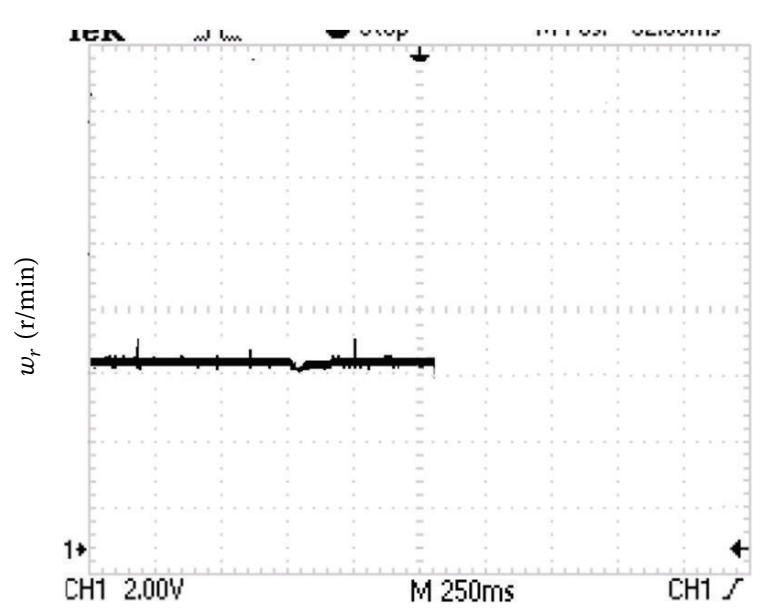

(a) Speed wave

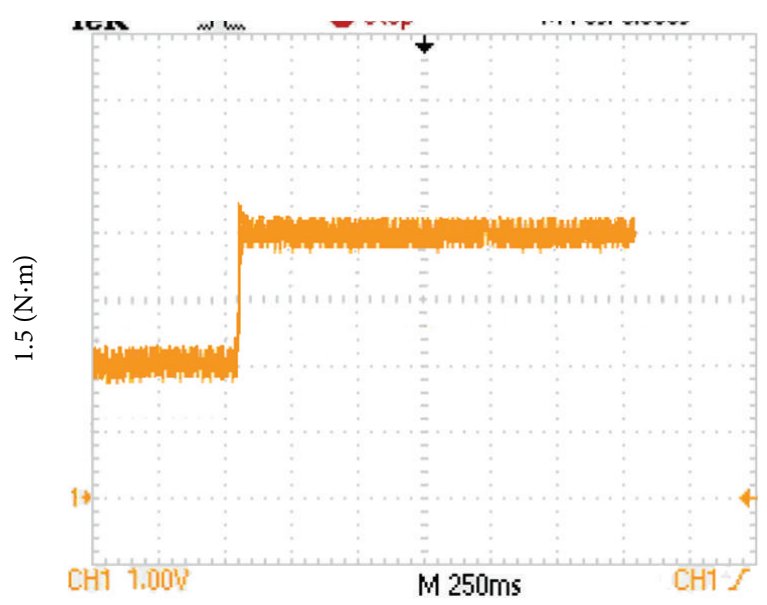

(b) Electromagnet torque wave

Figure 10: Experiment waves under LSSVM-ADRC method when given speed is $1500 \mathrm{r} / \mathrm{min}$ and load changes from $3 \mathrm{~N} \cdot \mathrm{m}$ to $6 \mathrm{~N} \cdot \mathrm{m}$.

adopted. The rectifier module uses diode and inverter module uses MOSFET. The current sensor CSNE151-100 is selected to sample PMSM stator currents. The voltage sensor JLBV1 is used to sample the stator voltage. The rotor speed of PMSM is measured by mechanical speed sensor, the type of which is BENTLY 330500.

The given speed is $700 \mathrm{r} / \mathrm{min}$ and load torque changes from 0 to $3 \mathrm{~N} \cdot \mathrm{m}$. The rotor speed waves are shown in Figures 7 and 8 under ADRC speed regulator and LSSVM-ADRC speed regulator, respectively.

The given speed is $1500 \mathrm{r} / \mathrm{min}$ and load torque changes from $3 \mathrm{~N} \cdot \mathrm{m}$ to $6 \mathrm{~N} \cdot \mathrm{m}$. The speed waves are shown in Figures 9 and 10 under ADRC speed regulator and LSSVM-ADRC speed regulator, respectively.

From Figures 7-10, it can be seen that, based on LSSVMADRC method, system responsiveness has been greatly improved; at the same time, system anti-interference ability has been improved to a large extent. It is consistent with the simulation results.

\section{Conclusion}

An improved method of PMSM vector control is proposed in the paper. The ADRC speed regulator is designed. Then, LSSVM optimal regression model is derived and embedded in the ADRC controller. ADRC observation precision and dynamic response of the system are improved. The system anti-interference ability is further improved. Finally, the current sensor, voltage sensor, and speed sensor are chosen to sample PMSM current, voltage, and speed. Experimental platform is constructed to verify the effectiveness of the proposed method.

\section{Conflict of Interests}

The authors declare that there is no conflict of interests regarding the publication of this paper.

\section{Acknowledgment}

This paper is supported by the Fundamental Research Funds for the Central Universities (2014MS89) and (2014QN46).

\section{References}

[1] H. Zhu, X. Xiao, and Y.-D. Li, "Stator flux control scheme for permanent magnet synchronous motor torque predictive control," Proceedings of the Chinese Society of Electrical Engineering, vol. 30, no. 21, pp. 86-90, 2010.

[2] J. Faiz and S. H. Mohseni-Zonoozi, "A novel technique for estimation and control of stator flux of a salient-pole PMSM in DTC method based on MTPF," IEEE Transactions on Industrial Electronics, vol. 50, no. 2, pp. 262-271, 2003.

[3] M. Kazerooni, S. Hamidifar, and N. C. Kar, "Analytical modelling and parametric sensitivity analysis for the PMSM steadystate performance prediction," IET Electric Power Applications, vol. 7, no. 7, pp. 586-596, 2013.

[4] F. J. Lin, Y. C. Hung, and M. T. Tsai, "Fault-tolerant control for six-phase PMSM drive system via intelligent complementary sliding-mode control using TSKFNN-AMF," IEEE Transactions on Industrial Electronics, vol. 60, no. 12, pp. 5747-5762, 2013.

[5] S. H. Li and H. Gu, "Fuzzy adaptive internal model control schemes for PMSM speed-regulation system," IEEE Transactions on Industrial Informatics, vol. 8, no. 4, pp. 767-779, 2012.

[6] C. L. Xia, J. X. Zhao, Y. Yan, and T. N. Shi, "A novel direct torque control of matrix converter-fed PMSM drives using duty cycle control for torque ripple reduction," IEEE Transaction on Industrial Electronics, vol. 61, no. 6, pp. 2700-2713, 2014.

[7] H. Liu and S. Li, "Speed control for PMSM servo system using predictive functional control and extended state observer," IEEE Transactions on Industrial Electronics, vol. 59, no. 2, pp. 11711183, 2012.

[8] Z. Wang, Y. Zheng, Z. Zou, and M. Cheng, "Position sensorless control of interleaved CSI fed PMSM drive with extended Kalman filter," IEEE Transactions on Magnetics, vol. 48, no. 11, pp. 3688-3691, 2012.

[9] Y. Da, X. Shi, and M. Krishnamurthy, "A novel universal sensor concept for survivable PMSM drives," IEEE Transactions on Power Electronics, vol. 28, no. 12, pp. 5630-5638, 2013. 
[10] B. Q. Li and H. Lin, "Direct control of current vector for surfacemounted permanent magnet synchronous motor," Proceedings of the Chinese Society of Electrical Engineering, vol. 31, no. 1, pp. 288-294, 2011.

[11] Y. Xu and Y. Zhong, "A novel direct torque control strategy of permanent magnet synchronous motors based on duty ratio control," Transactions of China Electrotechnical Society, vol. 24, no. 10, pp. 27-32, 2009.

[12] D. Sun, Y.-K. He, and Z.-Y. He, "Fault tolerant inverter based direct torque control for permanent magnet synchronous motor," Journal of Zhejiang University (Engineering Science), vol. 41, no. 7, pp. 1101-1131, 2007.

[13] S. He, A. R. Qiu, and X. M. Yuan, "Direct torque control of permanent magnet synchronous motor with SVM," Micromotors, vol. 41, pp. 6-8, 2008.

[14] L. Tang, L. Zhong, M. F. Rahman, and Y. Hu, "A novel direct torque controlled interior permanent magnet synchronous machine drive with low ripple in flux and torque and fixed switching frequency," IEEE Transactions on Power Electronics, vol. 19, no. 2, pp. 346-354, 2004.

[15] J. Xu, Y. Xu, and J. Feng, "Direct torque control of permanent magnet synchronous machines based on modified integrator," Transactions of China Electrotechnical Society, vol. 19, no. 7, pp. 77-80, 2004.

[16] D. Sun and Y. K. He, "Space vector modulated based constant switching frequency direct control for permanent magnet synchronous motor," Proceeding of the CSEE, vol. 25, pp. 112116, 2005.

[17] Y. P. Liu, "Space vector modulated direct torque control for PMSM based on ADRC," Electric Power Automation Equipment, vol. 31, no. 11, pp. 78-82, 2011.

[18] J. Q. Han, "From PID technique to active disturbance rejection control technique," Control Engineering of China, vol. 9, pp. 13$18,2002$.

[19] J. Q. Han, Active Disturbance Rejection Control Technique, National Defense Industry Press, Beijing, China, 2008.

[20] C. Peng, G. Liu, and H. Sun, "Wind speed forecasting based on wavelet decomposition and differential evolution-support vector machine for wind farms," Electric Power Automation Equipment, vol. 32, no. 1, pp. 9-13, 2012.

[21] Y. Zhang, Least Squares Support Vector Machines Inverse Control of Two-Motor Variable Frequency Speed-Regulation Systems, Jiang Su University, 2011.

[22] X. Shi, Z. Liu, M. Fu, and J. Wang, "Course control of air cushion vehicle based on SVM-ADRC," Journal of Huazhong University of Science and Technology (Natural Science Edition), vol. 40, no. 5, pp. 59-63, 2012.

[23] Z. C. Wu, Q. D. Ouyang, and Z. W. Hu, "Polarimetric SAR image classification using watershed-transformation and support vector machine," Geomatics and Information Science of Wuhan University, vol. 37, no. 1, pp. 7-10, 2012. 

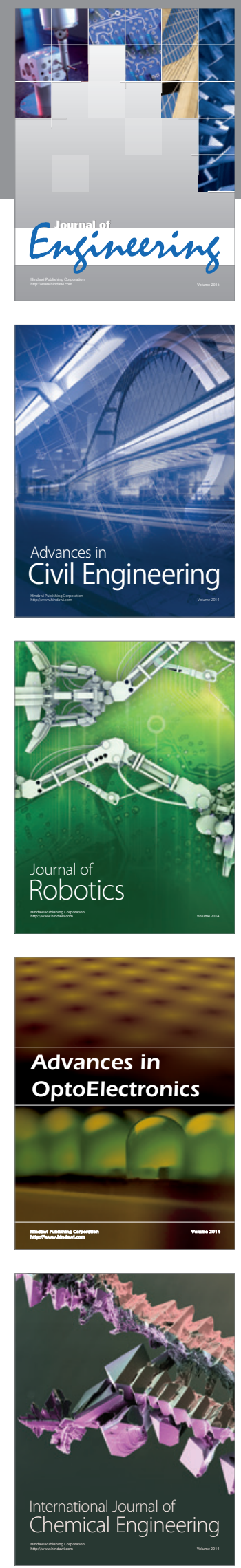

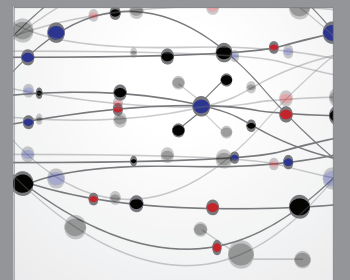

The Scientific World Journal
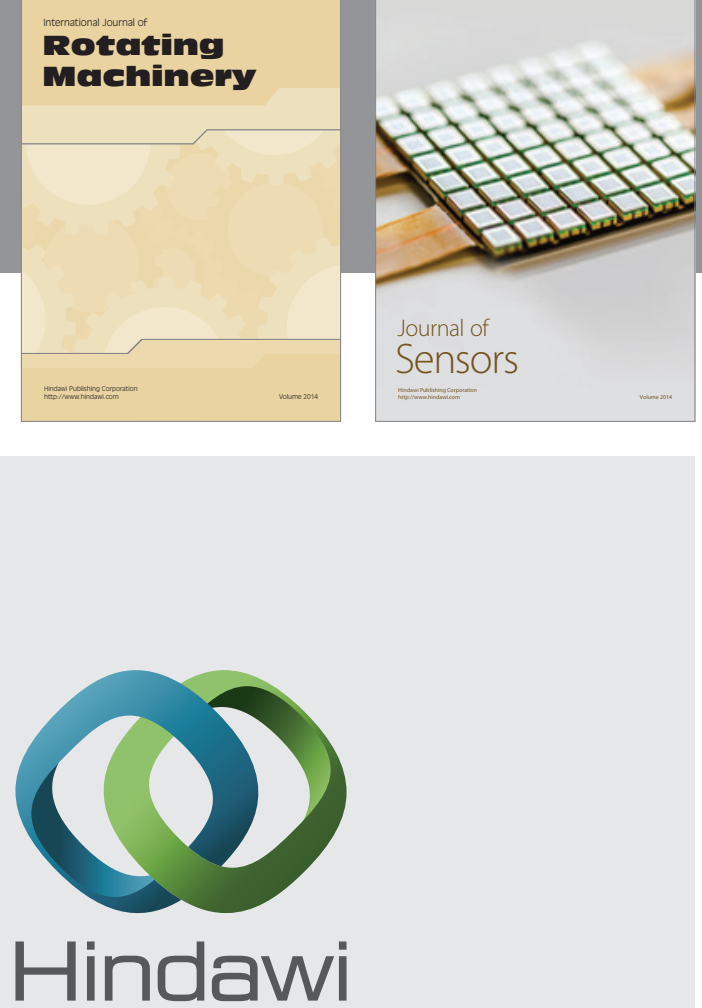

Submit your manuscripts at http://www.hindawi.com
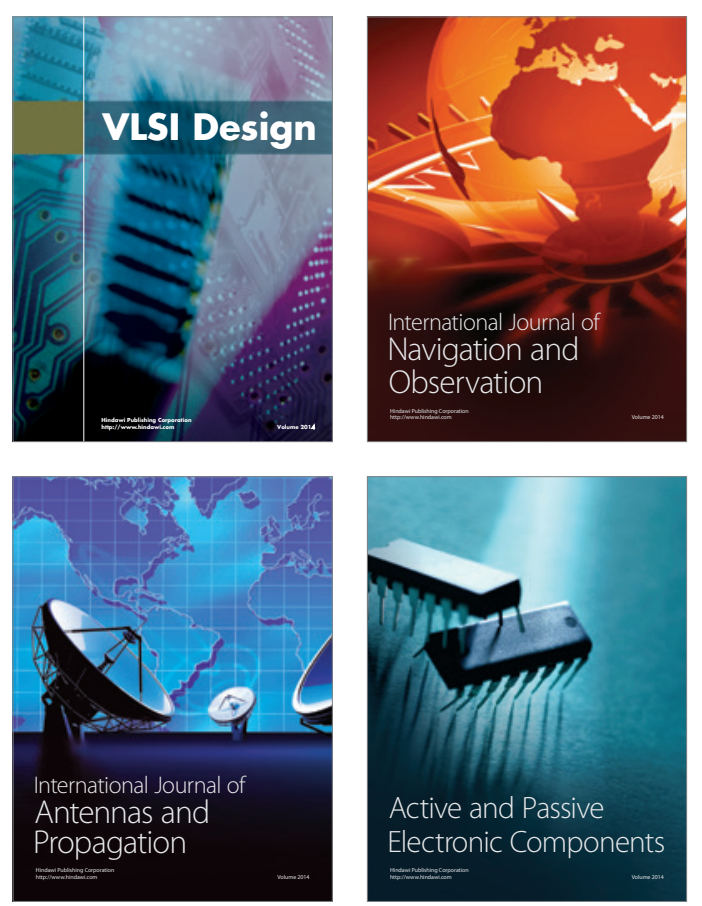
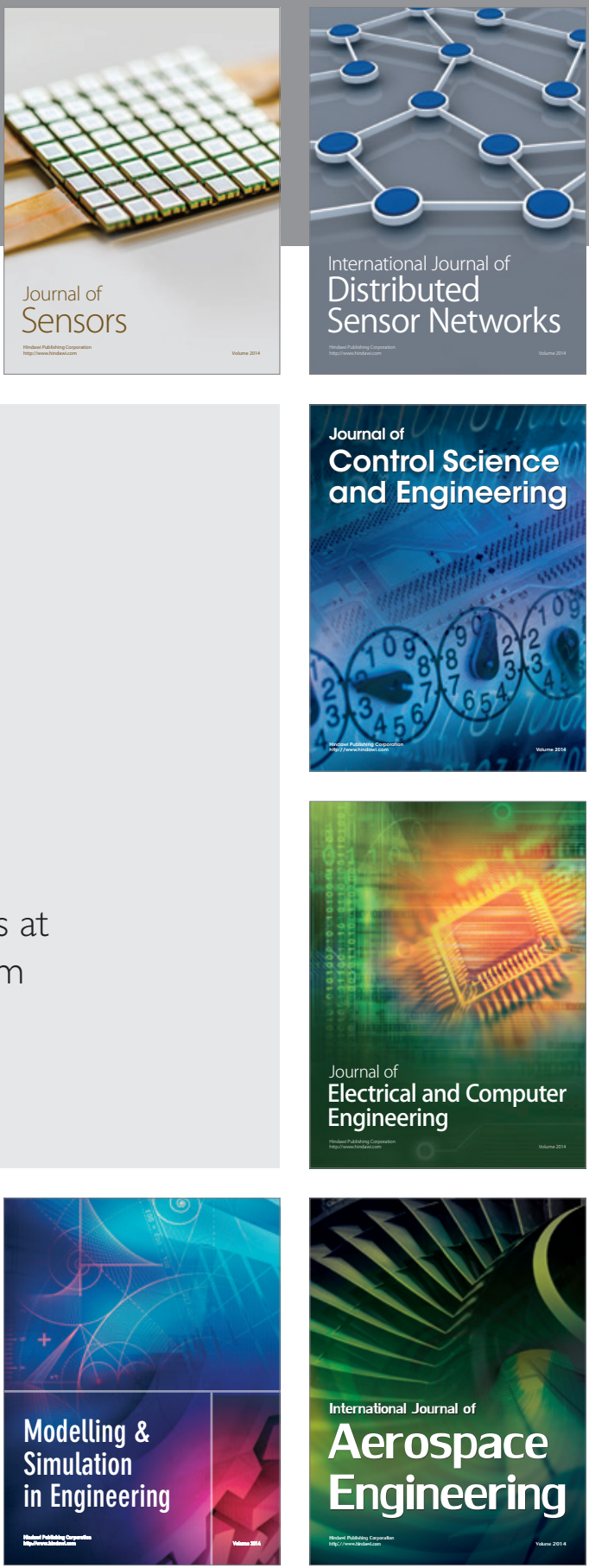

Journal of

Control Science

and Engineering
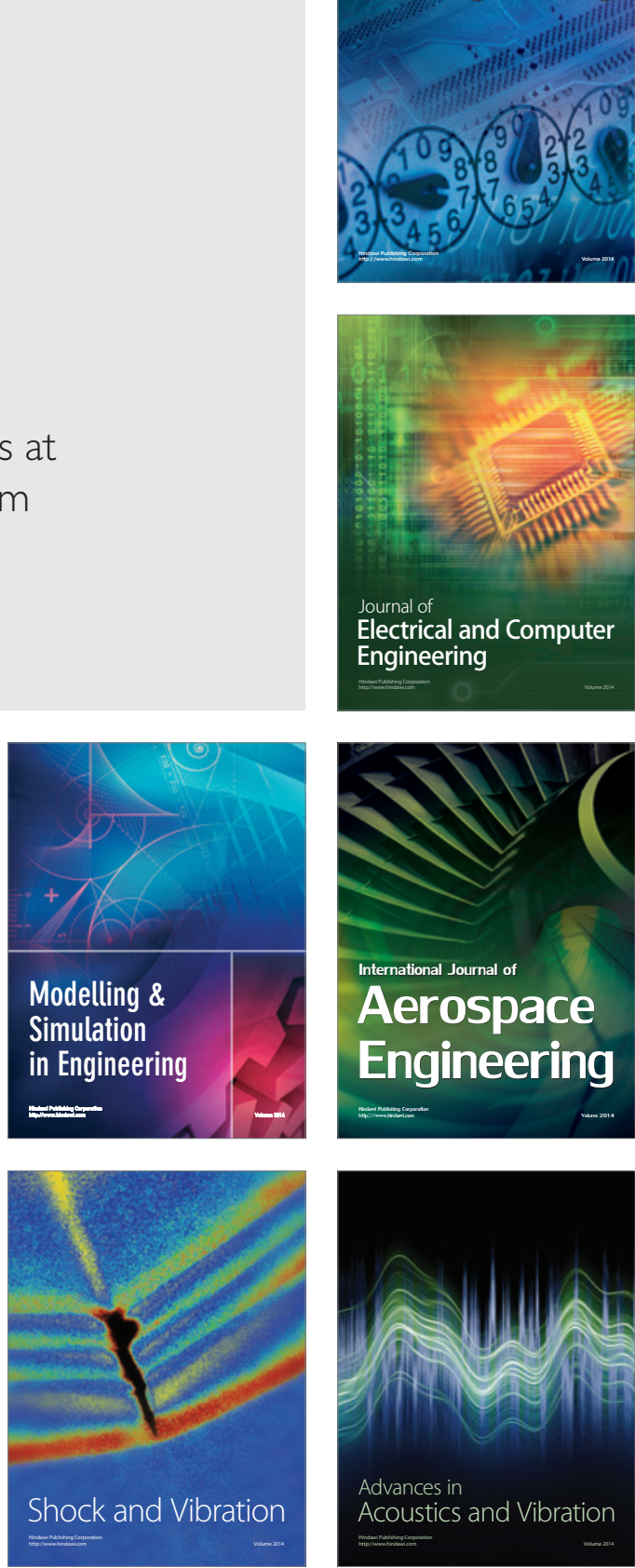